\title{
ARTICLE
}

\section{Personality disorder: its impact on staff and the role of supervision}

\author{
Estelle Moore
}

\begin{abstract}
Estelle Moore is a consultant
clinical and forensic psychologist,

and since 2001 the lead psychologist

for the Centralised Groupwork

Service based in the Newbury

Therapy Unit at Broadmoor Hospital,

UK. Prior to her current post she

worked for 7 years on a dedicated

unit for young male offender

patients with personality disorder in

a high-security hospital.

Correspondence Estelle Moore,

Lead Psychologist, Centralised

Groupwork Service, Broadmoor

Hospital, Crowthorne RG45 7EG, UK.

Email: estelle.moore@wlmht.nhs.uk
\end{abstract}

\section{SUMMARY}

Over the past decade attention to the provision of healthcare for individuals with personality disorder, particularly those who pose a risk to others, has substantially increased. Keeping pace with such developments with a suitably trained, consistent and motivated workforce, interfacing health and criminal justice systems where necessary, presents an enormous challenge. Staff must be experts in managing conflict at every level, while sustaining an optimistic and therapeutic orientation. Boundaried relationships provide the context for recovery for patients. Key principles and practices likely to promote resilience in personality disorder services, with a focus on the role of supervision, are outlined in order to support staff in keeping themselves afloat, their patients safe, and their services on target.

\section{DECLARATION OF INTEREST}

None.

operate as a protective factor for vulnerable persons (Fonagy 1997). Staff working with patients with a high propensity to act dangerously cannot operate safely without the support of colleagues and within an informed system that is designed to allow space for reflection.

However, as inquiries into systems at risk have illustrated, it is often those with the least training and fewer forums for accessing knowledge who spend the longest periods of time in contact with detained patients (Melia 1999; Storey 2000). Associated as it is with unresolved distress, the task of creating a healthy environment for patients with personality disorder is difficult, particularly if there has been previous interpersonal violence.

This article addresses some key factors in the professional training and development of staff who work in personality disorder services. It is assumed that staff appreciate the value of and need for a robust and healthy working alliance with service users (Safran 1993), which can confer a protective and healing advantage for their recovery: 'the chance to build a life' (Haigh 2002). The challenge is to bring about change by helping both service users and staff to develop the capacity to tolerate dissonance without precipitating crises that derail the process of intervention (Jones 2007).

$$
\text { (Scanlon 2009: p. 133) }
$$

Spending time in the company of people with personality disorder is emotionally demanding (Cox 1996; Alwin 2006; Kurtz 2007; Aiyegbusi 2009). Such complex work hardly gets a mention when things are going well, and perhaps rightly so, as it is the service recipients who make the changes, which in turn can re-establish the confidence of others in them. Conversely, when things go wrong, the effect for all can be devastating.

In an ideal world, professional carers are trained to approach their task in a systematic way, have the advantage of peer support from colleagues who understand the aims of the job, and use both educational and supervisory frameworks for guidance. Training provides an academic understanding of personality disorder and can make an important difference to the extent to which problematic behaviour can be tolerated. A capacity to understand traumatic interpersonal situations is likely to limit their impact, and to

\section{The interpersonal impact of personality disorder}

Arising from a complex interplay of genetic and environmental influences, personality disorder is undoubtedly shaped by psychosocial adversity usually physical, sexual and/or emotional abuse - which leads to chronic distress and interpersonal disadvantage (Box 1).

If a person has a diagnosis of personality disorder, they are likely to suffer more, and for longer, with other illnesses (Duberstein 1997; Paris 2001; Taylor 2006). Almost by definition, you are more likely to have been misunderstood, compared with others and unfavourably judged against community standards. Offenders with personality disorder can present simultaneously as 'fearsome perpetrators and traumatised victims' (Adshead 2008), their vulnerability masked by the threat they simultaneously pose (Schafer 2003). 
BOX 1 Core problems associated with personality disorder

- Difficulties in asking for help, presenting in 'crisis mode'

- Ambivalence about and rejection of treatment

- Lack of trust in others; fear of intimacy

- Compulsion to re-enact damaging aspects of formative relationships

- Needing opportunities to discharge psychic tension

Additional issues that increase risk to self and others include:

- misinterpretation of the motives of others, particularly when emotionally aroused

- 'pseudo-attachment' to helpers, who become vehicles for their unbearable emotion

- use of controlling and manipulative strategies to restore coherence to their sense of self

- taking action before thinking (impulsivity)

- being in an unknown environment: The greater the alienation from a secure base the greater the tendency to avoidance and unprovoked violence' (Holmes 1996)

The three clusters of personality disorder in DSM-IV (American Psychiatric Association 1994) include criteria that are best understood as an expression of the range of distinguishable defences that patients employ in their reactions to distress (Box 2). Put another way, most symptoms and signs of personality disorder are a means of coping with reactions to unbearable people in past or present time (Vaillant 1994), usually people in caring roles.

It is therefore not surprising that powerful feelings between patients and their professional carers are an inevitable aspect of therapeutic relationships; and are not always positive (Hayes 2004). In an early description of 'hateful patients' in general practice, Groves (1978) articulated the 'physician's dread' at encountering: the 'clinger' (who evokes aversion), the 'demander' (who evokes the desire to counter-attack), the 'help rejecters' (who evoke depression), and the 'self-destructive deniers' (who evoke malice and rejection).

Although such pejorative labels are rarely helpful in treatment, they resonate with clinicians because they give voice to real experiences. The feelings of patients towards clinicians (with origins in earlier experiences) constitute 'transference'; 'countertransference' includes the feelings stirred up in the clinician, and the clinician's projections onto the patient. When staff refer to a patient as 'difficult', they may not just be describing a set of clinical signs/symptoms, but rather their own

state of being/mind in that person's presence over time (Hinshelwood 1999).

The distinguishable defences that patients with personality disorder employ with staff tend to generate distinguishable reactions in professionals. Patients with Cluster A disorders often engender professional detachment and distance because of problems with engagement. Paranoid-schizoid functioning exposes staff on wards to high levels of projections, especially of intense persecutory anxieties, the processing of which is extremely emotionally taxing (Aiyegbusi 2009). Alliances robust enough for the treatment of personality disorder can be destabilised by the presence of active and intrusive psychotic symptoms (Taylor 2006). Patients with Cluster $C$ disorders may struggle to ask for help; or engage obsessionally with it.

There is some clinical consensus that Cluster B personality disorders in particular (including psychopathy; Hare 1998) have a substantial impact on carers (National Institute for Mental Health in England 2003; Rigby 2004; Bland 2005; Perseius 2007). Staff can become the target of intolerable feelings (of guilt, anxiety, depression, jealousy, hostility, neediness). Clarke $\&$ Ndegwa (2006) observed patterns of emotional abuse of staff by patients in a forensic medium secure unit. Male staff were vulnerable to reacting punitively; female staff were confronted with both subtle and explicit sexual harassment, or invited to behave flirtatiously as a means of charming away hostility. Patients with Cluster B disorders

\section{B0X 2 DSM-IV classification of personality disorder (Axis II)}

Cluster A: odd or eccentric disorders

- Paranoid personality disorder: irrational suspicions and mistrust of others

- Schizoid personality disorder: lack of interest in social relationships, seeing no point in sharing time with others, anhedonia, introspection

- Schizotypal personality disorder: odd behaviour or thinking

Cluster B: dramatic, emotional or erratic disorders

- Antisocial personality disorder: pervasive disregard for the law and the rights of others

- Borderline personality disorder: extreme 'black and white' thinking, instability in relationships, self-image, identity and behaviour, often leading to self-harm and impulsivity
- Histrionic personality disorder: pervasive attention-seeking behaviour, including inappropriately seductive behaviour and shallow or exaggerated emotions

- Narcissistic personality disorder: pervasive pattern of grandiosity, need for admiration, and a lack of empathy

Cluster C: anxious or fearful disorders

- Avoidant personality disorder: social inhibition, feelings of inadequacy, extreme sensitivity to negative evaluation and avoidance of social interaction

- Dependent personality disorder: pervasive psychological dependence on other people

- Obsessive-compulsive personality disorder: rigid conformity to rules, moral codes and excessive orderliness

(American Psychiatric Association 1994) 
may elicit care in ambivalent or hostile ways, which unconsciously confront or confirm their core beliefs about themselves and the world. Services working with people with personality disorder must anticipate and have a framework for addressing such needs.

\section{Different disciplinary experience}

The intensity of the exposure to difficult emotions within mental health services varies by profession. Nurses are required to relate to patients for prolonged periods of time (e.g. 8-hour shifts) and are therefore less protected than those (e.g. psychiatrists and psychologists) who provide sessional input to teams. Theirs is a highly specialised task, which is being redefined in various settings as a 'behavioural technician' role (Clarke 2006) or a unit-based therapy assistant. Inevitable differences of views between disciplines, and by role, can generate conflict in teams.

Henceforth in this article, the generic term 'staff' will refer to all mental healthcare workers notwithstanding these differences.

\section{Common issues for staff in personality disorder services}

Primary tensions in services for individuals who are legally detained, either under the Mental Health Act or in prison, oscillate between care and control, voluntary consent to treatment and coercion (Meux 2006). Staff are likely to struggle with their experience of patients as 'good' v. 'bad', a person who is possible to include/treat, or preferably exclude; a (rescuable) victim or a (to be avoided) perpetrator (Box 3).

\section{Tensions between personal and professional identities}

Staff in mental healthcare and penal settings are advised to operate with neutrality, to dress and behave professionally, and not to 'bring themselves' to work. Nevertheless, the 'person' is the first thing patients notice about their therapists: appearance, general manner, age, gender, disability, weight, height, skin colour, dress and hairstyle are 'all mutually assessed at some level before any words are spoken' (Scaife 2001a: p. 39).

Professionalism is, of course, essential, but can belie the impact of operating in settings where power and hierarchy are defining features of the organisation, and the working conditions can be traumatic:

'working only with violent persons in closed settings for sustained periods of time is too great a stress for staff members who seek to preserve a therapeutic orientation' (Roth 1985: p. 228).
BOX 3 'Toxic transference' in personality disorder services: common tests of staff integrity

Service users may:

- compare various members of nursing and multidisciplinary teams and their decisions

- provide minimal information to a member of staff to see how they cope

- make high numbers of complaints

- question others with the same therapist/nurse about actions that person took previously

- refuse to follow recommendations thereby emphasising staff vulnerability, not their own

- seek to relate to staff by adopting their language, style and affectations

- single staff out for special attention/comment, gifts or favours, criticism or assault

- play different professionals off against one another, exploiting normal inter-professional rivalries

- flirt with or reject staff

What can happen to staff exposed to such pressures? Significant emotional stress can overflow into their personal lives and can create fears even within their families (Bowers 2000). Repeated encounters with disturbing material at work can have an impact on choices beyond work: how people dress, conduct themselves, the relationships they form or avoid, and how they raise their children. Collaboration in the workplace flounders where differences between staff members' responses exist and, crucially, are not safely explored. Some common patterns in the 'interpersonal dance' (Duggan 2005) between patients with personality disorder and staff are outlined below.

\section{The pull to punish}

People-centred occupations are intrinsically stressful (Coffey 1999). Staff working with patients who have been violent are likely to be concerned about being the recipient of attacks and of being identified as aggressors (Doctor 2008). Some therapeutic practices, such as large community meetings, can be experienced by staff as 'too risky' (Moore 2006). Interactions which alter or flatten the balance of power between staff and patients can generate a tendency to overcontrol in staff who are anxious about losing power. Bullying, intimidation and assaults on patients by staff have been associated with circumstances in which there are no safeguards on imbalances of power, and the majority operate in collusion with a custodial regime (Blom-Cooper 1992; Fallon 1999). 
Obviously, a workforce needs to feel confident and skilled in managing high-risk situations effectively. Staff who are well trained in the management of violence describe the experience of feeling physically safe in the presence of patients with personality disorder, yet emotionally vulnerable (Kurtz 2007). Hence, physical security is only part of the task of the service overall: the emotional world of the unit cannot be ignored.

\section{Displacement and 'acting out' of distress}

'Acting out' is an analytic phrase which implies the non-conscious and unplanned behavioural 'acting out' of intolerable feelings, impulses and beliefs, without the capacity to contain or manage those in other ways. It should not be confused with the sort of performance that an actor consciously engages in as part of a pre-determined role.

In the 'culture' of personality disorder services, it may still covertly be deemed unprofessional to admit to having or expressing personal feelings or emotions about patients' actions and, perhaps even more so, about the response of colleagues to challenging behaviour. If this is the case, then emotions can be dislocated or transposed and reattached to another idea (Vaillant 1994). Frontline staff in a range of settings who are interviewed about job-related stress more often implicate working conditions and organisational pressures as more problematic for them than contact with patients (Kurtz 2005). It is possible that it is much easier to transfer (displaced) feelings of anxiety and frustration onto concrete external issues than give voice to emotions about patients.

Personal reactions may be masked as professional opinions. The term 'splitting' is common parlance within multidisciplinary teams struggling to contain divergent views about how best to respond to challenging behaviour. Mirroring the primitive defence mechanism, through which 'good' and 'bad' objects are set in opposition, a patient's behaviour can provoke different members of the team to ally to a greater or lesser extent with one another either in defence of or in opposition to the patient.

If there is a discrepancy between a personal reaction to behaviour (e.g. serious self-harm/shock and anger) and a professional intervention (calm and neutral), how does it get resolved? Norton $\&$ Dolan (1995) have illustrated the process by which 'many psychiatric hospitals are in effect, like acting out patients, in that they tend to display only a narrow repertoire of relatively inflexible responses' to distress. Acting out in the context of Cluster B personality disorder is a process through which the direct behavioural expression of an unconscious wish/conflict allows the individual to remain unaware of the idea/emotion that the action accompanies.

Acting out serves two functions: expressive (communicating intense and urgent need) and defensive (preventing the destruction of integrity) (Campling 1996). Staff who are experienced in working with people with personality disorder typically recognise the behavioural component of acting out as a surface marker of a concurrent emotional problem, but even so, such actions can impair collaboration.

Those not immediately involved with the patient (but perhaps with responsibilities such as supervisors and managers) can also evidence intense reactions. The more frustration staff experience, the more the patient acts out and stalemate can ensue (Norton 1995). Regulation of affect, acknowledgement of the need for staff and patients to vent emotion, and adherence to relationship roles, create the security that is essential for therapeutic responses when patients are both distressed and highly distressing in the actions they undertake (Adshead 2002).

\section{Complex and damaging repetitions}

Individuals who were traumatised within their family environment are vulnerable in terms of the long-term maladaptive effect of their reaction to the trauma, and their reduced resilience in the face of it (Fonagy 1997). Lack of resolution of abusive experience, often via inhibition of reflective functioning, reduces the likelihood of forming meaningful and successful adult relationships (McGauley 2006).

Unresolved distress is communicated via uncomfortable feelings that carers experience and through behavioural re-enactments of past traumatic experiences. Staff actions/interpersonal styles often trigger such conflict re-enactments through the process of 'projective identification' (whereby 'bad' feelings, impulses and beliefs are projected onto staff, who experience the patient's emotions as their own). For example, a frightened patient may consider his named nurse to be persecutory and be unusually hostile towards her (due to fear), while the named nurse experiences her patient as frightening. Staff may find themselves subjected to the hatred and rejection that patients were exposed to in earlier circumstances (Neeld 2009). The challenge of distinguishing which feelings belong to whom, when and possibly why, is essential to the building of psychotherapeutic alliances, especially in forensic settings (Aiyegbusi 2004). 


\section{Boundary violations}

The experience of a therapeutic alliance can trigger in patients an 'aching awareness' (Campling 1996) of the extent of former neglect and loss, and frantic demands for staff time can be the consequence. This often materialises (and can become dangerous) at breaks or terminations in therapeutic contact. At such times patients may draw on contact-maintaining activities (e.g. threats to self-harm), and/or further seek 'concrete evidence' (e.g. a sign of commitment or a declaration of intimacy) of attachment from staff (Campling 1996). This does not mean that therapy is necessarily contraindicated, but that attachment-related distress must be anticipated. If the capacity for mentalisation in close relationships (i.e. the understanding of behaviour in terms of the associated mental states in self and others) is not recovered in therapy, change is unlikely. Patients with borderline personality disorder have been shown to be particularly vulnerable to sideeffects of individual sessions that activate their attachment systems (Fonagy 2006).

Feeling attraction or love for a therapist can be a normal part of therapy that requires a 'working through' by the patient within a healthy alliance (Disch 1993). Ideally, the therapist also works through their negative and positive emotions towards the patient. However, difficulties arise if any eroticism of the transference or countertransference becomes secret and acted upon. Although the most notorious boundary violations are sexual (and may initially be viewed as positive by both the member of staff and the patient), there are other types of boundary violations that are also harmful such as breaches of confidentiality and scapegoating.

An established author in this field, Gutheil (2005) cautions as to the need for 'non-judgemental clarity' in the area of boundary problems, given the 'perils of confusion'. He distinguishes 'boundary crossing' (transient, non-exploitative deviations from 'classical'/general practice that do no harm, and may even facilitate alliance) from 'boundary violation' (essentially harmful deviations from the normal parameters of treatment). One essential test of this distinction is whether the events in question can be discussed during therapy or supervision. 'Explore before action' is a useful recommendation for staff responses when working with people with personality disorder.

No discipline is immune to perpetrating misuses of professional power; neither gender nor seniority are necessarily protective factors. Any actions that meet the needs of the staff member rather than those of the patient are ethically unjustifiable (Pope 1991; Peterson 1992; Thomas-Peter 2000).
This is because such violations exploit power disparities and imbalance relations in favour of the more powerful (Llewelyn 2009).

The damage to patients of breaches in the professional duty of care is phenomenal, exacerbating loss of trust in carers, and extensive distress and isolation that may endure for many years (Disch 1993; Thomas-Peter 2000). Equally, the damage caused by boundary violations has an impact on the wider institution, undermining its capacity for effective treatment (Gutheil 2003).

Specific impacts on staff range from the experience of constant anxiety in the workplace to suspension and dismissal (with concomitant loss of job, status and income). Those who are witness to colleagues 'crossing the line' are likely to experience feelings of uncertainty about previous evaluations of their colleagues' work, divided loyalties and moral distress (Peternelj-Taylor 2003), such that the directive always to place the patient's welfare above all other considerations can become difficult to follow (Thomas-Peter 2000). All involved know that boundary violations are harmful, but they still occur.

Early detection of warning signs ('red flag' systems) is perhaps the best form of prevention: violations rarely happen 'out of the blue' (Gutheil 2005). Self-assessment checklists are available that promote self-monitoring for 'blind spots' in relational security (e.g. Love 2001). Slippages (behaviour that falls into the grey area between staying within or crossing boundaries) preceding violation are known to include overfamiliarity, inappropriate favouritism and the exchange of promises/gifts (Webb 1997; Walker 1999). A lack of consequence for seemingly minor breaches decreases the likelihood of arresting toxicity in alliances before enduring harm has occurred (Box 4). The boundary seesaw model (Hamilton 2010) supports a collective conceptualisation of boundaries in practice and generates clear guidelines for staff on how to relate in a balanced and professional way.

In summary, defensive attitudes and practices are known to obstruct therapeutic opportunities at every level of the institution (Menzies Lyth 1960; Norton 1995). Conflict in professional relationships is inevitable, but the risk is higher in personality disorder services because, by definition, people with personality disorder have a compromised set of skills to enable them to handle distress safely. The context for the management of Cluster B personality disorder is often controlling and hierarchical, which gives rise to another layer of manipulation (and iatrogenic outcomes; Fonagy 2006; Jones 2007). When patients and staff rely on (maladaptive) survival skills, this maintains 
potentially unhealthy relationships in systems that have the power to detain (Box 3). Policies on conduct (and what will happen in the event of misconduct) should be accessible to all.

\section{What can be done to create healthy and hopeful services for personality disorder?}

The goal of the healthy personality disorder service is to promote safe containment or, in National Health Service terminology, security. What are some of the essential elements in such a system of care?

Mackie (2009) usefully describes three types of containment that reduce fear in staff and patients. 'Concrete' containment is embodied in the buildings, bricks and mortar, doors, walls and locks of the hospital/unit. 'Chemical' containment (medication) represses some disturbance and can provide respite from disabling (Axis 1) symptoms. 'Emotional' containment is generated within safe, stable and supportive relationships with people in any setting, allowing people who are alienated and disturbed/aggressive to be re-introduced to 'doses of reality' and the company of others. A fourth form of containment is procedural, and it is provided in policies involving multiple checks and balances that institutions put in place to ensure safety. Since exposure to intense emotional experience associated with psychopathology is inevitable (Cox 1996), the primary objectives for the clinical workforce become: selection, training, support and effective management.

\section{Selection}

\section{Choosing staff who can 'contain'}

Who might be best suited to working with people with personality disorder? Such a question is of interest to anyone seeking to recruit motivated, secure and reliable colleagues. People may be attracted to such posts for a whole range of reasons, most of which, it has been suggested, pale into insignificance in the face of the dynamic processes that they will encounter in the workplace. Scanlon $\&$ Adlam (2009) refer to the notion of 'psychic survival' as a key competence: conferring the ability to retain a clear sense of separateness, to be able to think your own thoughts while remaining functional and effective.

Similarly, Maden (2006) notes that different skills are required of staff working in personality disorder services than other mental healthcare services, and that the ability of staff to resolve conflict assertively might be a useful predictor of a future resilience in the role. Thomas-Peter $\mathcal{E}$ Garratt (2000) recommend that staff who appear vulnerable to establishing unethical relations should not be selected for roles in forensic environments. This can be difficult to identify during a selection process, and may also change over the duration of a career. Relationship tensions outside the workplace can put staff at risk of emotional strain and potentially unhelpful selfdisclosure, communicating mutuality rather than collaboration for treatment purposes (Walker 1999). Procedures such as personal health checks, certainly pre-employment and regularly (annually) post-employment, have been proposed for staff in regular contact with patients with personality disorder (Lord 2003; Sainsbury Centre for Mental Health 2009).

A genuine interest in the work is likely to be a helpful starting place. The capacity to form secure attachments with others is also important, and has been associated with higher alliance ratings in psychotherapy services (Eames 2000).

\section{Staff motivations and interests}

Staff attitudes to their role as agents of help can make a difference to the nature and quality of the care patients receive. There is evidence that critical views about patients with enduring and complex disorders can change with psychoeducational training input (Finnema 1996; Willetts 1997; Hazelton 2006). Specifically, attributions about the causes of behavioural problems are important in determining the emotional and behavioural responses of staff.

Experience is another factor, with less-trained staff being more critical and emotionally cold, with higher levels of expressed emotion (Van Humbeeck 2003). Dennis \& Leach (2007) report high expressed emotion in male healthcare

BOX 4 Potentially unhelpful staff responses to 'toxic' challenges

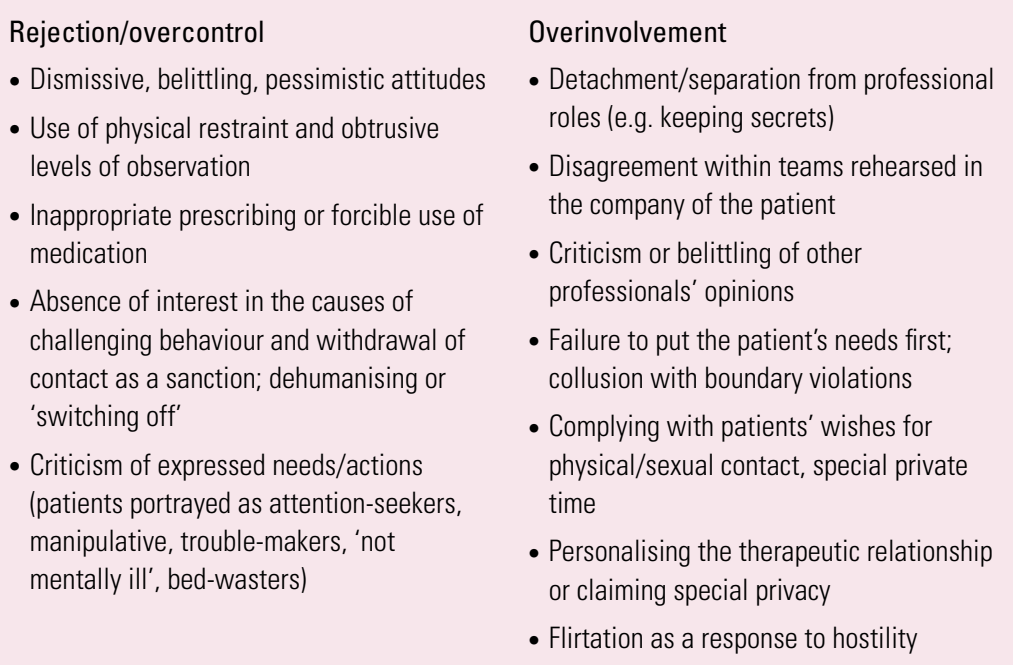


support staff who endorsed elements of burnout including depersonalisation and low personal accomplishment. High expressed emotion is linked to less favourable outcomes for patients in forensic services with complex needs, including personality disorder (Moore 2002). Views can shift considerably following experiences of assault: staff victims are more likely to express criticism and to reject patients in the immediate aftermath (Cottle 1995).

Mothersole (2000) highlights voyeuristic motivations, particularly in forensic units, whereby staff may gain a vicarious excitement/notoriety from their connection to certain offender patients.

\section{Training}

\section{Opportunities to learn about core competencies}

'Relational security' is dependent on a multidisciplinary workforce that can enhance and develop therapeutic programmes (Exworthy 2003). Working as a newcomer in a personality disorder service is likely to be highly anxietyprovoking: the process of induction and the behaviour and attitudes of key mentors make an important contribution. From the outset, the tensions between security and care will be evident to inexperienced staff (who may find themselves swinging between inclinations to care $v$. reject, or seek to protect $v$. punish, operate with too much confidence $v$. hesitation) as they make sense of how to amalgamate complex information about the clinical task.

Longer-serving/senior staff are role models (Crichton 1998), and much therefore depends on the psychological health of the unit. Whole teams and organisations can become dysfunctional, so that the external world reflects grave and disabling splits in the patients' internal world, in a 'some staff good, most staff bad' caricature (Tuck 2009). Learning to operate with self-awareness might be considered a fundamental skill, a prerequisite for working with people with personality disorder.

\section{What should the contents of a training package for staff on personality disorder units include?}

Health, safety, violence and risk training are typically mandatory. Service users with personality disorder have recommended that training staff to develop empathy and understanding of personality disorder would also be a good start (Haigh 2002). Skills in treating others respectfully while under pressure to do otherwise should probably be a fundamental training goal: understanding personality pathology and the nature of change provides an essential foundation (Livesley 2005).
A formal introduction as to what constitutes inappropriate interaction (Thomas-Peter 2000) and how to set and maintain boundaries are also core competencies. More complex interpersonal therapeutic skills including orientation to emotional availability for patients in distress (Zeddies 1999) typically demands longer postqualification training. Knowledge of the service content is also important: what range of services is available to the patients? What is the contribution of (other) disciplines? What are the politics of the setting? (Scaife 2001b: p. 249).

Training for staff must be well timed. For staff who appear 'burnt out' ('I've seen all this before, they'll never change, I'm basically here to pay the mortgage'), training may actually intensify such beliefs if mistimed. Extended contact with very slow-to-change populations can lead staff to identify with the hopelessness that patients encounter, and the 'no-win' position of offender patients in relation to the society that has excluded them (Lowdell 2009). Conversely, a risk for wellintentioned staff might be that they are seen as overattentive, perhaps too ready to do things for patients, rather than helping them to accomplish their own goals.

\section{Creating a context for boundaried practice: the clinical importance of supervision}

No one can entirely process emotional reactions at the time of their occurrence, and people will vary in their preparedness and ability to acknowledge or express uncomfortable feelings. Sometimes services claim to promote safe expression of feeling, while in reality they stigmatise and discriminate against those who give voice to any struggles. The term supervision is often misused in this way: staff thought to be 'at risk' who are directed to attend 'more supervision' might see this as a form of discipline rather than as a resource for safe exploration and learning.

Clear therapeutic objectives and clinical supervision provide the framework within which alliances for change can be generated with patients. Supervisory relationships should either preclude the simultaneous existence of relationships or, where dual relationships pertain (e.g., with a line manager and a clinical supervisor), this should be acknowledged and the implications addressed (Scaife 2001b: p. 45).

In essence, supervision refers to a range of key ideas (Scaife 2001b) about how to provide support, reflective space and function, regulation of the supervisee and the establishment of the 'limit[s] that promote integrity' (Katherine 1991). Empowerment of the supervisee is a key function 
of the supervisory alliance but is often poorly implemented in secure environments (Storey 2000). To managers less exposed to clinical challenges, supervision might be viewed as irrelevant to the task, ineffective, expensive and ultimately unavailable due to lack of good supervisors. Problems such as this must be addressed in any therapeutic service for patients with personality disorder. There are two primary aspects to supervision: (1) establishing and maintaining appropriate boundaries for professionals and services; and (2) attending to the needs (for safety, personal development, etc.) of the staff member.

Boundary setting and maintenance is therefore a key supervisory task often highlighted as lacking in the wake of enquiries (Exworthy 2003). Boundaries must be regarded as flexible standards of good practice, the application of professional judgements, and not as rigidly adhered to lists of 'generically forbidden behaviour' (Hermansson 1997; Gutheil 2003). Boundaries define relationships and roles. A good definition of the nature of 'boundary' in clinical practice is 'the edge of appropriate professional contact' (Gutheil 2005). Accepting boundaries implies that we acknowledge that 'there are limits to what we can do, with whom and when, central to which are a commitment to non-exploitation of the other, and trust' (Llewelyn 2009).

Boundaries are maintained, and limits set, by staff working in multidisciplinary teams via the communication of clear expectations about behaviour. Since exchanges between patients with personality disorder and staff can be 'covert' (Duggan 2005), it is very important that staff have a safe place to describe and discuss how best to respond to such challenges. Certain useful strategies for maintaining boundaries are co-working, allocation of roles, and sharing the burden in demanding work (Melia 1999).

\section{Support}

\section{The role of supervision in maintaining 'optimal' working alliances}

Supervision has a number of functions that are formative (lifelong learning and professional development), restorative (a space for support, shared understanding and acknowledgement of impacts), and normative (concerned with good practice standards). The supervisor's role is to attend both to the actions and reactions of the staff member and team, and to the knowledge, feelings and qualities that influence the alliance with the patient. The aim of the process is to ensure the best possible practice whatever the context, and to enhance the staff members' range and depth of clinical skills. Clinical supervision has been defined by Mothersole (2000) as a 'scheduled regular meeting in which a clinician meets with a fellow professional with the express purpose of examining their work'.

In the past, transfer to a colleague, team or service who could 'stand' the patient (Groves 1978) was considered a solution to patients who engendered difficult feelings in professionals. Nowadays, treatment alliances in personality disorder services ideally involve a level of compassionate neutrality on the part of the professional. It is helpful (with the assistance of supervision) to process challenging events without excessive aggression, outrage, withdrawal or compliance. An understanding of the unconscious message of challenging behaviour has the potential to arrest vicious cycles of rejecting re-enactments.

Some patients with personality disorder will be unaware of their impact on others, but are nevertheless held accountable for it, as if they could/should do something about this. Rather, it must be the staff who provide the routes to repair ruptures in professional alliances as they develop. Staff should not expect to like or be liked by all patients (Moran 1996). Nevertheless, they must always treat all services users with respect (Sainsbury Centre for Mental Health 2009).

It is essential for patients with personality disorder to experience clinicians as personal, human and authentic (Safran 1993). As Kraus \& Reynolds (2001) put it, 'the person in the clinician must meet the person in the patient'. The adoption of an inquisitive (not expert) stance enables staff to retrace steps in the interaction/series of encounters that have 'gone wrong', and to take the initiative in building and rebuilding bridges (Fonagy 2006).

Drawing on research involving others with serious and long-term mental health problems, Repper et al (1994) describe how successful staff realise the need to balance 'realism' (taking a longterm perspective) with optimistic hope of change and growth, appreciating that, given the nature of the patients' problems, recovery will be a fluctuating process.

\section{Group approaches to supervision}

\section{Reflective practice}

Reflective practice is a group technique which involves all professionals (regardless of experience or training) meeting together to talk about patients and their feelings towards them. This is recommended practice for all staff working with 
people with personality disorder as an essential part of the job (National Institute for Mental Health in England 2003). As the term implies, reflection is the opposite of operating mindlessly in response to problem behaviour, and reflective practice should increase the capacity of the organisation to mentalise. Reflective practice also allows for an external perspective on a clinical treatment system, which protects against boundary violations and abusive practice.

\section{Master classes}

Other types of group supervision may be helpful (Proctor 2001). Among the advantages of working with others is the mutual recognition of expertise (Scaife 2001b; p. 104). Some group supervision takes the form of a 'master class', with some supervisees acting as an audience. A disadvantage of this model can be that some staff feel deskilled as a consequence. This is particularly likely to happen in multidisciplinary forums where wide power differentials between staff exist. In participative and cooperative groups, responsibility for the tasks of the group is shared with a supervisor who teaches, encourages and facilitates. Although time can become an issue if not fairly shared, these models generally encourage skill development.

Peer surpervision

Peer supervision, as the name implies, involves colleagues in shared responsibility for supervision, leadership roles and responsibilities. Wellfunctioning peer groups can provide safe and trustable working alliances. Bland \& Rossen (2005) describe the role of clinical nurse specialists in the provision of group supervision for nursing teams working with people with borderline personality disorder, and the resultant enhancement of job satisfaction for all. A possible difficulty with peer supervision as the sole source of reflective practice is that it may exclude other professionals and increase the risk of splits in a multidisciplinary team.

\section{Responsive management}

\section{Learning from incidents}

During the early 1990s, the introduction of the serious incident review had the adverse effect of fostering a 'blame culture' in some quarters of the healthcare service (Blumenthal 2001; Rose 2008). Analysis of errors (e.g. root cause analysis) generates knowledge, but sometimes at a cost: over the past decade, there has been an expansion in the formal management procedures for dealing with bad outcomes. If an incident has occurred, the inclusion of a range of staff, and the use of external facilitators, promotes the production of reports to operational boards, whose task is then to analyse the failure of the system as a whole.

Rose (2008) has argued that good patient care is best served by the use of an inclusive review process that combines peer group frontline expertise with management inquiry skills. Untoward incidents in large organisations often have complex interrelationships and need to be reviewed in this light (Vincent 2000). Recent work on the dissemination of learning points from service incident reviews has highlighted how critical the process of communicating the findings is (Thinn 2010). Frequently, the learning cycle is incomplete because key points are not accessibly and specifically communicated to front-line staff.

Key events can have a profound impact on individual clinicians and their inclination or suitability to remain in post. The impacts of the work (ranging from reading forensic casenote material, being subject to verbal abuse or complaint, and/or suffering/witnessing a violent attack) and management handling of these occurrences, have all been articulated by staff working with people with personality disorder as areas of concern (Bowers 2000). When incidents of crisis/acute distress in the clinical work occur early in the person's career and are survived, this can enhance resilience. Senior managers have a responsibility to understand and anticipate the potential for these events, and to operate to minimise any 'casualties' of the process. All staff involved in any complaints or investigatory process should have access to (external) support (Bowers 2000) (Box 5).

\section{Evidence of the benefits of supervision: enhancing morale}

As Scaife (2001b) observes, supervision is not the 'panacea for dealing with [all] work-related issues'. The aims and purposes of supervision may not be realised, and typically especially not for those most at risk of defaulting from the professional task. Equally, many of the functions of supervision can be achieved in other ways via less 'formal' relationships (over a cup of coffee) in the workplace. However, in support of its role, vital in modern, effective healthcare systems, there is evidence that supervision is associated with positive outcomes (Milne 2007).

The benefits of participation in clinical supervision can be highly significant: enhancing a sense of coherence and creativity, reducing job-related strain and increasing satisfaction (Berg 1999). A number of factors contribute 
BOX 5 Management-led strategies to promote health and recovery in personality disorder services

- Retain professional roles: always keep the duty of care in focus

- Select motivated staff

- Provide training on personality disorders, boundary setting and maintenance

- Attend to changes in staff attitude/interest/morale

- Promote an 'empathic balance' between trust and control: share decisions (rules agreed by peers are more likely to be accepted than those imposed by parental figures)

- Establish a culture of reflective enquiry: 'Can we safely explore together what might be happening here?

- Include appropriate use of humour

- Respond swiftly but calmly to rule-breaking; operate with 'firmness without retribution'; do not retaliate; do not over-react

- Provide opportunities for detained persons (and staff) to 'let off steam'

- Communicate the learning points from serious incidents/set-backs specifically and directly to all staff

to rewarding, 'happy' work environments in mental healthcare (Bowers 2009): services that are well organised, that have clearly defined and consistently implemented policies (e.g. relating to abuse directed at staff), that educate and rotate their staff, and that see retaining a sense of humour as valued and essential (Moran 1996).

The positive impacts of working with individuals with personality disorder are rarely explicitly articulated. Even the work of the best-intentioned staff in a personality disorder service is likely to be replete with failures to retain impartiality. Being a therapist of a patient with borderline personality disorder is 'to be acutely reminded that one is a human being' (Layden 1993). If staff feel secure in the support of colleagues, with a sense of purpose in their encounters, they stand some chance of accepting distress, sometimes responding with creativity, and structuring the relational environment such that those in their company might begin to do the same.

'It is always encouraging to see newer residents being encouraged, cajoled, soothed, challenged and constrained by residents further on in therapy, who a few months earlier, were exhibiting the same sorts of destructive ambivalence' (Campling 1996: p. 544).

What could be more rewarding than that?

\section{References}

Adshead G (2002) Three degrees of security: attachment and forensic institutions. Criminal Behaviour and Mental Health 12: S31-45.

Adshead G, Bose S, Cartwright C (2008) Life after death: working with men who have killed. In Murder (ed R Doctor): 9-33. Karnac.

Aiyegbusi A (2004) Thinking under fire: the challenge for forensic mental health nurses working with women in secure care. In Working Therapeutically with Women in Secure Mental Health Settings (eds N Jeffcote, N Watson): 108-19. Jessica Kingsley Publishers.

Aiyegbusi A (2009) The dynamics of difference. In Therapeutic Relationships with Offenders. An Introduction to the Psychodynamics of Forensic Mental Health Nursing (eds A Aiyegbusi, J Clark-Moore): 69-80. Jessica Kingsley Publishers.

Alwin N, Blackburn R, Davidson K, et al (2006) Understanding Personality Disorder: A Report by the British Psychological Society. British Psychological Society.

American Psychiatric Association (1994) Diagnostic and Statistical Manual of Mental Disorders (4th edn) (DSM-IV). APA

Berg A, Hallberg IR (1999) Effects of systematic clinical supervision on psychiatric nurses' sense of coherence, creativity, work-related strain, job satisfaction and view of the effects from clinical supervision: a pre-post test design. Journal of Psychiatric and Mental Health Nursing 6: 371-81.

Bland AR, Rossen E (2005) Clinical supervision of nurses. Working with patients with borderline personality disorder. Issues in Mental Health Nursing 26: 507-17.

Blom-Cooper L (1992) Report of the Committee of Inquiry into Complaints about Ashworth Hospital (Cm 2028). HMSO.

Blumenthal S, Lavender T (2001) Violence and Mental Disorder: A Critical Aid to the Assessment and Management of Risk. Jessica Kingsley Publishers.

Bowers L, McFarlane L, Kiyimba F, et al (2000) Factors Underlying and Maintaining Nurses' Attitudes to Patients with Severe Personality Disorder. Final Report to National Forensic Mental Health R\&D. Department of Mental Health Nursing, City University.

Bowers L, Allan T, Simpson A, et al (2009) Morale is high in acute inpatient psychiatry. Social Psychiatry Psychiatric Epidemiology 44: 39-46.

Campling P (1996) Maintaining the therapeutic alliance with personalitydisordered patients. Journal of Forensic Psychiatry 77: 535-50.

Clarke A, Ndegwa D (2006) Forensic personality disorder in an MSU: lessons learnt after two years. British Journal of Forensic Practice 8 (suppl 4): 29-33.

Coffey M (1999) Stress and burnout in forensic community mental health nurses: an investigation of its causes and effects. Journal of Psychiatric and Mental Health Nursing 6: 433-43.

Cottle M, Kuipers L, Murphy G, et al (1995) Expressed emotion, attributions and coping in staff who have been victims of violent incidents. Mental Handicap Research 8 (suppl 3): 168-83.

Cox M (1996) Psychodynamics and the special hospital 'road blocks and thought blocks'. In Forensic Psychotherapy: Psychodynamics and the Offender Patient (eds C Cordess, M Cox): 433-48. Jessica Kingsley Publishers.

Crichton JHM (1998) Psychodynamic perspectives on staff response to inpatient misdemeanour. Criminal Behaviour and Mental Health 8: 266-74.

Dennis AM, Leach C (2007) Expressed emotion and burnout: the experience of staff caring for men with learning disability and psychosis in a medium secure setting. Journal of Psychiatric and Mental Health Nursing 14: 267-76.

Disch E (1993) When intimacy goes awry. Dulwich Centre Newsletter, 3\&4: $21-6$.

Doctor R (ed) (2008) Introduction. In Murder. 1-7. Karnac.

Duberstein PR, Conwell Y (1997) Personality disorders and completed suicide: a methodological and conceptual review. Clinical Psychology: Science and Practice 4: 359-76. 


\section{MCO answers \\ $\begin{array}{lllll}1 b & 2 d & 3 b & 4 c & 5 a\end{array}$}

Duggan C (2005) Dynamic therapy for severe personality disorder. In Personality Disorders and Serious Offending: Hospital Treatment Models (eds C Newrith, C Meux, P Taylor): 146-60. Hodder Arnold.

Eames V, Roth A (2000) Patient attachment orientation and the early working alliance: a study of patient and therapist reports of alliance quality and ruptures. Psychotherapy Research 10 (suppl 4): 421-34.

Exworthy T, Gunn J (2003) Taking another tilt at high secure hospitals. The Tilt Report and its consequences for secure psychiatric services. British Journal of Psychiatry 182: 469-71.

Fallon P, Bluglass R, Edwards B, et al (1999) Report of the Committee of Inquiry into the Personality Disorder Unit, Ashworth Special Hospital. (Vol. 1) (Cm 4194, II). TSO (The Stationery Office).

Finnema EJ, Louwerens JW, Slooff CJ, et al (1996) Expressed emotion on long-stay wards. Journal of Advanced Nursing 24: 473-8.

Fonagy P, Target M (1997) Attachment and reflective function: their role in self-organization. Development and Psychopathology 9: 679-700.

Fonagy P, Bateman A (2006) Progress in the treatment of borderline personality disorder. British Journal of Psychiatry 188: 1-3

Groves JE (1978) Taking care of the hateful patient. New England Journal of Medicine 298: 883-7.

Gutheil TG, Gabbard G0 (2003) Misuses and misunderstandings of boundary theory in clinical and regulatory settings. Focus 1: 415-21.

Gutheil TG (2005) Boundary issues and personality disorders. Journal of Psychiatric Practice 11: 421-9.

Haigh R (2002) Services for People with Personality Disorder: The Thoughts of Service Users. Department of Health (http://www.dh.gov. uk/prod_consum_dh/groups/dh_digitalassets/@dh/@en/documents/ digitalasset/dh_4130844.pdf).

Hamilton L (2010) The boundary seesaw model: good fences make for good neighbours. In Using Time, Not Doing Time: Practitioner Perspectives on Personality Disorder and Risk (eds A Tennant, K Howells): 181-94. John Wiley \& Sons.

Hare R (1998) The Hare PCL-R: some issues concerning its use and misuse. Legal and Criminological Psychology 3: 99-119.

Hayes JA (2004) The inner world of the psychotherapist: a program of research on countertransference. Psychotherapy Research 14 (suppl 1): 21-36.

Hazelton M, Rossiter R, Milner J (2006) Managing the 'unmanageable': training staff in the use of dialectical behaviour therapy for borderline personality disorder. Contemporary Nurse 21: 120-30.

Hermansson G (1997) Boundaries and boundary management in counselling: the never-ending story. British Journal of Guidance \& Counselling 25: 133-46.

Hinshelwood RD (1999) The difficult patient. The role of 'scientific psychiatry' in understanding patients with chronic schizophrenia or severe personality disorder. British Journal of Psychiatry 174: 187-90.

Holmes J (1996) Attachment, Intimacy, Autonomy: Using Attachment Theory in Adult Psychotherapy. Jason Aronson.

Jones L (2007) latrogenic interventions with 'personality disordered' offenders. Psychology, Crime \& Law 13: 69-79.

Katherine A (1991) Boundaries: Where You End and I Begin. Simon \& Schuster.

Kraus G, Reynolds DJ (2001) The 'ABC's' of the Cluster B's: identifying, understanding, and treating Cluster B personality disorders. Clinical Psychology Review 21: 345-73.

Kurtz A (2005) The needs of staff who care for people with a diagnosis of personality disorder who are considered a risk to others. Journal of Forensic Psychiatry and Psychology 16: 399-422.

Kurtz A, Turner K (2007) An exploratory study of the needs of staff who care for offenders with a diagnosis of personality disorder. Psychology and Psychotherapy 80: 421-35

Layden MA, Newman CF, Freeman A, et al (1993) Cognitive Therapy of Borderline Personality Disorder. Allyn \& Bacon.
Livesley WJ (2005) Principles and strategies for treating personality disorder. Canadian Journal of Psychiatry 50: 442-50.

Llewelyn S, Gardner D (2009) Boundary issues in clinical psychology. Clinical Psychology Forum 193: 5-9.

Lord A (2003) Working with personality-disordered offenders. Forensic Update 73: 31-9.

Love CC (2001) Staff-patient erotic boundary violations. Journal of Psychosocial Nursing 7: 4-7.

Lowdell A, Adshead G (2009) The best defence: institutional defences against anxiety in forensic services. In Therapeutic Relationships with Offenders. An Introduction to the Psychodynamics of Forensic Mental Health Nursing (eds A Aiyegbusi, J Clark-Moore): 53-67. Jessica Kingsley Publishers.

Mackie S (2009) Reflecting on murderousness: reflective practice in secure forensic settings. In Therapeutic Relationships with Offenders. An Introduction to the Psychodynamics of Forensic Mental Health Nursing (eds A Aiyegbusi, J Clark-Moore): 93-104. Jessica Kingsley Publishers.

Maden T (2006) DSPD: origins and progress to date. British Journal of Forensic Practice 8: 24-8.

McGauley G, Rubitel A (2006) Attachment theory and personality disordered patients. In Personality Disorder and Serious Offending: Hospital Treatment Models (eds C Newrith, C Meux, P Taylor): 69-80. Hodder Arnold.

Melia P, Moran T, Mason T (1999) Triumvirate nursing for personality disordered patients crossing the boundaries safely. Journal of Psychiatric and Mental Health Nursing 6: 15-20.

Menzies Lyth I (1960) The Functioning of Social Systems as a Defence Against Anxiety - A Report. Centre for Applied Social Research, Tavistock Institute of Human Relations.

Meux C, Taylor P (2006) Settings for the treatment of personality disorder. In Personality Disorder and Serious Offending: Hospital Treatment Models (eds C Newrith, C Meux, P Taylor): 205-15. Hodder Arnold.

Milne D (2007) An empirical definition of clinical supervision. British Journal of Clinical Psychology 46: 437-47.

Moore E, Yates M, Mallindine C, et al (2002) Expressed emotion between staff and patients in forensic services: changes in relationship status at 12 month follow up. Legal and Criminological Psychology 7: 203-18.

Moore C, Freestone M (2006) Traumas of forming: the introduction of community meetings in the Dangerous and Severe Personality Disorder (DSPD) environment. Therapeutic Communities 27: 193-209.

Moran T, Mason T (1996) Revisiting the nursing management of the psychopath. Journal of Psychiatric and Mental Health Nursing 3: 189-94.

Mothersole G (2000) Clinical supervision and forensic work. Journal of Sexual Aggression 5 (suppl 1): 45-58.

National Institute for Mental Health in England (2003) Breaking the Cycle of Rejection: The Personality Disorder Capabilities Framework. 49. Department of Health

Neeld R, Clark T (2009) The patient, her nurse and the therapeutic community In Therapeutic Relationships with Offenders An Introduction to the Psychodynamics of Forensic Mental Health Nursing (eds A Aiyegbusi, J Clark-Moore): 157-70. Jessica Kingsley Publishers.

Norton K, Dolan B (1995) Acting out and the institutional response. Journal of Forensic Psychiatry 6: 317-32.

Paris J, Zweig-Frank H (2001) A 27 year follow-up of patients with borderline personality disorder. Comprehensive Psychiatry 42: 482-7.

Perseius KI, Kaver A, Ekdahl S, et al (2007) Stress and burnout in psychiatric professionals when starting to use dialectical behavioural therapy in the work with young self-harming women showing borderline personality symptoms. Journal of Psychiatric and Mental Health Nursing 14: $635-43$

Peternelj-Taylor C (2003) Whistleblowing and boundary violations: exposing a colleague in the forensic milieu. Nursing Ethics 10: 526-37.

Peterson M (1992) At Personal Risk: Boundary Violations in ProfessionalClient Relationships. Norton. 
Pope KS, Vetter VA (1991) Prior therapist-patient sexual involvement among patients seen by psychologists. Psychotherapy 28: 429-38.

Proctor B, Inskipp F (2001) Group supervision. In Supervision in the Mental Health Professions. A Practioner's Guide (ed J Scaife): 99-121. Brunner-Routledge.

Repper J, Ford R, Crooke A (1994) How can nurses build trusting relationships with people who have severe and long-term mental health problems? Experiences of case managers and their clients. Journal of Advanced Nursing 19: 1096-104.

Rigby M, Langford J (2004) Development of a multi-agency experiential training course on personality disorder. Psychiatric Bulletin 28: 337-41.

Rose N (2008) Oxford serious incident review: 7 years on. Psychiatric Bulletin 32: 307-9.

Roth LH (ed) (1985) Clinical Treatment of the Violent Person. Guilford Publications.

Safran JD (1993) Breaches in the therapeutic alli ance: an arena for negotiating authentic relatedness. Psychotherapy 30: 11-24.

Sainsbury Centre for Mental Health (2009) Personality Disorder: A Briefing for People Working in the Criminal Justice System. Sainsbury Centre for Mental Health (http://www.scmh.org.uk/pdfs/personality_ disorder_briefing.pdf)

Scaife J, Walsh S (2001a) The emotional climate of work and the development of self. In Supervision in the Mental Health Professions. A Practitioner's Guide (ed J Scaife): 30-51. Bruner-Routledge.

Scaife J (2001b) Supervision in the Mental Health Professions. A Practioner's Guide. Brunner-Routledge.

Scanlon C, Adlam J (2009) Nursing dangerousness, dangerous nursing and the spaces in between: learning to live with uncertainties. In Therapeutic Relationships with Offenders. An Introduction to the Psychodynamics of Forensic Mental Health Nursing (eds A Aiyegbusi, J Clark-Moore): 127-42. Jessica Kingsley Publishers.

Schafer P, Peternelj-Taylor C (2003) Therapeutic relationships and boundary maintenance: the perspective of patients enrolled in a treatment program for violent offenders. Issues in Mental Health Nursing 24: 605-25.
Storey L, Minto C (2000) Mental health: the use of clinical supervision in secure environments. British Journal of Nursing 9: 2226-31.

Taylor PJ (2006) Co-morbidity and personality disorder: the concept and implications for treatment of personality disorder co-morbid with psychosis. In Personality Disorder and Serious Offending. Hospital Treatment Models (eds C Newrith, C Meux, P Taylor): 170-82. Hodder Arnold.

Thinn K (2010) Reporting on incidents. Health Service Journal May 11 (http://www.hsj.co.uk)

Thomas-Peter B, Garrett T (2000) Preventing sexual contact between professionals and patients in forensic environments. Journal of Forensic Psychiatry 11: 135-50.

Tuck G (2009) Forensic systems and organisational dynamics. In Therapeutic Relationships with Offenders. An Introduction to the Psychodynamics of Forensic Mental Health Nursing (eds A Aiyegbusi, J Clark-Moore): 43-52. Jessica Kingsley Publishers.

Vaillant GE (1994) Ego mechanisms of defence and personality psychopathology. Journal of Abnormal Psychology 103 (suppl 1): 44-50.

Van Humbeeck G, Van Audenhove C (2003) Expressed emotion of professionals towards mental health patients. Social Psychiatry and Psychiatric Epidemiology 12: 232-5.

Vincent C, Stanhope N, Taylor-Adams S (2000) Developing a systematic method of analysing serious incidents in mental health. Journal of Mental Health 9: 89-103.

Walker R, Clark JJ (1999) Heading off boundary problems: clinical supervision as risk management. Psychiatric Services 50: 1435-9.

Webb SR (1997) Training for maintaining appropriate boundaries in counselling. British Journal of Guidance \& Counselling 25 (suppl 2): 175-88.

Willetts LE, Leff J (1997) Expressed emotion and schizophrenia: the efficacy of a staff training programme. Journal of Advanced Nursing 26 : 1125-33.

Zeddies TJ (1999) Becoming a psychotherapist: the personal nature of clinical work, emotional availability and personal allegiances. Psychotherapy 36: 229-35.

\section{MCOs}

Select the single best option for each question stem

1 What are defences?:

a forms of martial art

b mechanisms that reduce the distress and conflict caused by specific experiences

c methods for negotiating a stage of development

d mechanisms to reduce psychological barriers

e ways of demonstrating psychological strengths.

2 'Acting out' is:

a disturbed patient behaviour

b all about breaking rules

c a way of letting off steam

$d$ a consequence of impulses that are difficult to verbalise

e a sign that staff are not in control of the unit.
3 Staff effectiveness in working with patients with personality disorder is likely to be predicted by their ability to:

a take the initiative in repairing ruptures in relations with colleagues

b mentalise under pressure

c ensure that their professional title is used at all times

d diagnose psychopathology

e write excellent reports about patients.

\section{Individuals with personality disorder} report that it is helpful when staff:

a react to behaviour

b withdraw contact as a sanction

c are firm yet fair and consistent in their approach

d use physical restraint

e change locations regularly.
5 To maintain boundaried relationships when working with people with personality disorder, it is recommended that staff:

a attend regular supervision to acknowledge (individual and group) interpersonal dynamics

b never disclose personal information about themselves

c only discuss treatment options with patients when absolutely necessary

$\mathrm{d}$ never disclose information that has been entrusted to them to other staff

e do not show their feelings. 